\title{
INTEGRATED EFFECT OF ASCORBIC ACID, CITRIC ACID AND CALCIUM LACTATE ON QUALITY AND SHELF-LIFE OF FRESH-CUT PAPAYA CUBES
}

\author{
Hafiz Khuram Wasim Aslam, ${ }^{1,}$, Muhammad Inam-ur-Raheem ${ }^{1}$, \\ Tahir Zahoor ${ }^{1}$ and Muhammad Shahid ${ }^{2}$
}

\author{
${ }^{1}$ National Institute of Food Science \& Technology, University of Agriculture, Faisalabad, Pakistan; \\ ${ }^{2}$ Depatrment of Biochemistry, University of Agriculture, Faisalabad, Pakistan \\ "Corresponding author's email: khuramwasimfsd@hotmail.com
}

\begin{abstract}
Current study was conducted to observe the effectiveness of firming agent (calcium lactate) integrated with anti-browning agents (ascorbic acid and citric acid) on the quality and shelf life of fresh cut papaya cubes under low temperature. Ripen and uniform sized papaya were minimally processed by washing, peeling, coring and cubing then treated with various concentration of calcium lactate $(0.8 \%, 1.6 \%$ and $2.4 \%)$ integrated with ascorbic acid (1.7\%) as well as citric acid (1.7\%). All samples after packing in plastic bags were refrigerated at $4 \pm 2{ }^{\circ} \mathrm{C}$ and analyzed quality characteristics after each 4 day interval. The results indicated that firmness and color $L^{*}$ value and acidity decreased while TSS, $\mathrm{pH}$, weight loss, $a^{*}$ and $b^{*}$ values increased during storage when compared with control. Moreover, periodic sensory evaluation showed that score in taste, texture, color, flavor and overall acceptability for papaya cubes decreased with respect to storage and treatment interaction. Calcium lactate @ 2.4\% integrated with citric acid @ 1.7\% and calcium lactate @ 2.4\% along with ascorbic acid @ 1.7\% showed significant storage stability for firmness, color, $\mathrm{pH}$, acidity and weight loss as well as sensory characteristics for as longer as 16 days of storage. Keywords: Papaya, fresh cuts, anti-browning agent, firming agent, sensory attributes.
\end{abstract}

\section{INTRODUCTION}

Papaya (Carica papaya $L$ ) is a fruit of the sub-tropical and tropical region of the world. Its production area has been increasing every year. Up to 2015-16, the total production of papaya fruit in Pakistan was about 8.732 thousand tones while growing on the area of 1.545 thousand hectares (Agricultural Statistics of Pakistan, 2015-16). Only puree and nectar is prepared for export purpose from papaya. Because it has very shorter shelf life due to climacteric nature so, it is difficult to send it in distant markets in fresh form. Papaya is a low caloric fruit and rich in dietary fiber, vitamin A, polysaccharide and lycopene (Wall et al., 2010) along some important minerals like phosphorous, potassium and magnesium. Additionally, it is rich in folate, pantothenic acid, and especially it is opulent in "papain" an enzyme, which aids the digestive system and efficiently treat the causes of allergies and trauma (Vij and Prashar, 2015). Due to which this fruit has many beneficial aspects especially in minimizing the risk of some serious human diseases like vomiting, diarrhea, dysentery, wounds, ulcers, toothache, coughs, sore throat, inflamed gums, obesity, diabetes and heart attacks. Any produce which has been washed, peeled, trimmed, sliced into required sizes, packed in packaging materials made up of plastic or glass and finally they are stored in refrigerated condition is known as fresh-cut produce (Waghmare and Annapure, 2013).

Fresh-cut technology is a complicated technology through which ripening and respiration processes can be delayed in fruits and vegetables for quite more time than normal to avoid their softening and spoilage problems (Jayathunge et al., 2013). Minimal processing of papaya is time and labor consuming as it is often eaten fresh, peeled, deseeded and cut into wedges. Hence, fresh-cut papaya has become increasingly popular among consumers due to its convenience. However, the main problems that are usually associated with fresh-cut papaya are the loss of weight, loss of firmness, depletion of nutritional value and development of high microbial loads (Pandey and Goswami, 2012). Inappropriate postharvest handling and processing can lead to outbreak of food borne illness and deterioration of physiological and chemical properties of fresh-cut papaya (Waghmare and Annapure, 2013). It has been reported that chlorine-based washing as a decontamination procedure has been widely adopted in the fresh-cut industry due to its ease of use (Akhtar et al., 2010). Certain enzymes like amylase polyphenol oxidase (PPO) and pectinase work efficiently in the presence of high temperature, environmental oxygen and high concentration of ethylene gas. Certainly, the fruit ripening is possible only in the presence of some enzyme like kinase, amylase, hydrolase and pectinase (Tirkey et al., 2014) but the most responsible enzyme is pectinase which works as one of the bond breaker between the pectin and as calcium and cause destruction of pectin from fruits. Therefore, it is needed to maintain the firmness and to give more shelf life than normal activity of pectinase enzyme (Akhtar et al., 2010). 
Cell wall of fruit contains one of the most important component "calcium" which is always in bound form along with pectin. That can be greatly supportive to maintain the required textural properties of fruits. Calcium concentration in fruits initiated to lower down promptly with the action of pectinase enzyme. Therefore, fruits may be spoil very rapidly. So, it is needed to control ethylene production, lower down the pectinase activity and /or increase the Ca content in the cell wall of fruits. Considerable number of scientists found that shelf life and firmness of different fruits like apples (Rocculi et al., 2004), strawberry (Aguayo et al., 2006), litchi (Sivakumar and Korsten, 2006), banana (Vilas-Boas and Kader, 2006), jackfruit bulbs (Saxena et al., 2006), mushroom (Jafri et al., 2013) and cantaloupe (Luna-Guzman and Barrett, $2000)$ is improved by using calcium (1-4\%) at 90-95\% RH even at $10^{\circ} \mathrm{C}$.

However, by applying 3-4\% calcium lactate solution. Some problem has been noted especially physical appearance and taste of the treated fruits. On the other hand, it was noted that $3 \%$ calcium chloride impart changes in taste of apple slices (Almenar et al., 2008). While there is not any taste change found when calcium lactate applied on the apple slices with the same ratio. Furthermore, Pandey and Goswami (2012) found that $\mathrm{CaCl}_{2} 2 \%$ works better than control and improve taste and enhance shelf life even at $95 \% \mathrm{RH}$ and $5^{\circ} \mathrm{C}$ temperature.

Citric acid along with Calcium lactate (0.1-3.0\%) can impart positive effect to maintain the fruit textural properties and citric acid has been used for fresh cut fruit to reduce superficial pH of fruits (Jayathunge et al., 2014) Current project was designed to enhance the availability of papaya fruit as ready to serve/consume/process by the use of fresh cut technology and to determine the integrated effect of firming and anti-browning agents on physicochemical and sensory characteristics of fresh-cut papaya.

\section{MATERIALS AND METHODS}

The ripen and equal size papaya fruit (Bombay variety) having yellow color taken from local market of Faisalabad. For processing, Papaya fruits were transported to the fruits and vegetables processing laboratory of National Institute of Food Science and Technology, University of Agriculture Faisalabad, where the fruits were washed with sterilized water to remove physical and biological contaminants on fruits. Washed papaya then cut into halves, removed black color seeds, peel it with hand peeler and then cut into uniform cubes with $2 * 2 * 2$ inches. Uniform cubes were dipped for 6 minutes in solution of $0.8 \%$ calcium lactate $+1.7 \%$ citric acid $\left(\mathrm{T}_{1}\right)$, $1.6 \%$ calcium lactate $+1.7 \%$ citric acid $\left(\mathrm{T}_{2}\right), 2.4 \%$ calcium lactate $+1.7 \%$ citric acid $\left(\mathrm{T}_{3}\right), 0.8 \%$ calcium lactate $+1.7 \%$ ascorbic acid $\left(\mathrm{T}_{4}\right), 1.6 \%$ calcium lactate $+1.7 \%$ ascorbic acid $\left(\mathrm{T}_{5}\right), 2.4 \%$ calcium lactate $+1.7 \%$ ascorbic acid $\left(\mathrm{T}_{6}\right)$. Treated cubes were gently air dried and then packed into good quality air tight plastic bag $(100 \mathrm{~g} / \mathrm{bag})$. Packed papaya stored in refrigerator chamber at $4^{\circ} \mathrm{C} \pm 2$. During storage samples were analyzed at regular intervals of $0,4,8,12$ and 16 days for firmness with the help of TA-XT2i texture analyzer (Stable Micro System, Ltd. in Godalming, Surrey, UK) with a $50 \mathrm{~kg}$ load cell equipped with $5 \mathrm{~mm}$ diameter cylindrical probe after four days intervals (Wall et al., 2010). Colour of papaya cubes was measured through Hunter Lab Colourimeter, (LabScan XE, Hunter Lab Calourimeter, DP-9000 D25A, Reston, USA) (Tirkey et al., 2014). Weight loss was determined by taking difference between the initial weight of each papaya sample and the weight taken after each four day (Akhtar et al., 2010). $\mathrm{pH}$ and total soluble solids (TSS) were determined with the help of $\mathrm{pH}$ meter and refractometer respectively for each treatment during mentioned storage intervals (Jayathunge et al., 2013). 9-point hedonic scale ( 1 = Dislike extremely, $2=$ dislike very much, 3 = dislike moderately, $4=$ dislike slightly, $5=$ neigther like nor dislike, $6=$ like slightly, $7=$ like moderately, 8 like very much and $9=$ like extremely) were used to evaluate the sensory attributes (color, flavor, taste, texture and overall acceptability) as presented by Meilgaard et al. (2007). Triplicate samples were analyzed by using CRD with factorial arrangement by using SPSS.

\section{RESULTS AND DISCUSSION}

Firmness: A highly significant $(\mathrm{P}<0.01)$ influence of chemical additives (calcium lactate, citric and ascorbic acid) on storage periods and their interaction on the firmness of fresh cut papaya cubes observed during statistical analysis. About firmness (Table 1), application of $2.4 \%$ calcium lactate +1.7 citric acid maintained the highest fruit firmness (2.39a) followed by $2.4 \%$ calcium lactate +1.7 ascorbic acid (2.35b) and $1.6 \%$ calcium lactate +1.7 citric acid $(2.23 \mathrm{c})$. Whereas, the lowest firmness $(1.75 \mathrm{~g})$ was showed by control sample. The interaction between storage days and treatments also exhibited a decreasing trend in fruit firmness during whole storage period. But the highest decrease in firmness(N) (2.400.91) was noted in untreated sample followed by $0.8 \%$ calcium lactate $+1.7 \%$ ascorbic acid $(\mathrm{N})(2.42-1.55)$ and $0.8 \%$ calcium lactate $+1.7 \%$ citric acid $(2.43-1.59)$ whereas, the minimum drop in fruit firmness $(2.50-2.16)$ was observed in papaya cubes treated with $2.4 \%$ calcium lactate $+1.7 \%$ citric acid. Similarly, Raheem et al. (2013) noted that the firmness in fresh cut guava increased with the increase in concentrations of calcium chloride. Moreover, Rodrigues et al. (2006) recorded that the reduction in the firmness of freshcut fruits during storage is due to dissolution of middle lamella and subsequent cell separation because of the enzymatic activity of pectin esterase.

Total Soluble Solids (TSS): The statistical outcomes regarding the TSS of fresh-cut papaya cubes showed considerable influence by various treatments of calcium lactate combined with citric acid and ascorbic acid on TSS for 
Effect of calcium lactate, citric and ascorbic acid on papaya

Table 1. Effect of calcium lactate along with citric acid and ascorbic acid during storage on the firmness (N) of fresh-cut papaya cubes.

\begin{tabular}{|c|c|c|c|c|c|c|}
\hline \multirow{2}{*}{ Treatments } & \multicolumn{5}{|c|}{ Storage } & \multirow{2}{*}{ Means } \\
\hline & $\mathbf{0}$ & 4 & 8 & 12 & 16 & \\
\hline $\mathrm{T}_{0}$ & $2.40 \pm 0.02$ & $2.15 \pm 0.03$ & $1.84 \pm 0.04$ & $1.43 \pm 0.01$ & $0.91 \pm 0.03$ & $1.75 \mathrm{~g}$ \\
\hline $\mathrm{T}_{1}$ & $2.43 \pm 0.01$ & $2.31 \pm 0.01$ & $2.15 \pm 0.02$ & $1.93 \pm 0.05$ & $1.59 \pm 0.02$ & $2.08 \mathrm{e}$ \\
\hline $\mathrm{T}_{2}$ & $2.47 \pm 0.01$ & $2.39 \pm 0.02$ & $2.28 \pm 0.02$ & $2.12 \pm 0.02$ & $1.91 \pm 0.02$ & $2.23 \mathrm{c}$ \\
\hline $\mathrm{T}_{3}$ & $2.50 \pm 0.03$ & $2.55 \pm 0.01$ & $2.44 \pm 0.02$ & $2.32 \pm 0.01$ & $2.16 \pm 0.02$ & $2.39 \mathrm{a}$ \\
\hline $\mathrm{T}_{4}$ & $2.42 \pm 0.02$ & $2.30 \pm 0.02$ & $2.13 \pm 0.01$ & $1.90 \pm 0.04$ & $1.55 \pm 0.01$ & $2.06 \mathrm{f}$ \\
\hline $\mathrm{T}_{5}$ & $2.46 \pm 0.04$ & $2.38 \pm 0.01$ & $2.26 \pm 0.01$ & $2.09 \pm 0.04$ & $1.87 \pm 0.03$ & $2.21 \mathrm{~d}$ \\
\hline $\mathrm{T}_{6}$ & $2.50 \pm 0.02$ & $2.52 \pm 0.03$ & $2.39 \pm 0.03$ & $2.26 \pm 0.02$ & $2.07 \pm 0.04$ & $2.35 \mathrm{~b}$ \\
\hline Means & $2.45 \mathrm{a}$ & $2.37 \mathrm{~b}$ & $2.21 \mathrm{c}$ & $2.01 \mathrm{~d}$ & $1.72 \mathrm{e}$ & \\
\hline
\end{tabular}

Table 2a. Effect of calcium lactate along with citric acid and ascorbic acid during storage on the TSS of fresh-cut papaya cubes.

\begin{tabular}{lcccccc}
\hline \multirow{2}{*}{ Treatments } & \multicolumn{5}{c}{ Storage } & \multirow{2}{*}{ Means } \\
\cline { 2 - 5 } & $\mathbf{0}$ & $\mathbf{4}$ & $\mathbf{8}$ & $\mathbf{1 2}$ & $\mathbf{1 6}$ & $12.28 \mathrm{a}$ \\
$\mathrm{T}_{0}$ & $10.98 \pm 0.01$ & $11.52 \pm 0.03$ & $12.17 \pm 0.01$ & $13.94 \pm 0.02$ & $12.80 \pm 0.02$ & $11.60 \mathrm{~d}$ \\
$\mathrm{~T}_{1}$ & $10.96 \pm 0.03$ & $11.17 \pm 0.02$ & $11.50 \pm 0.02$ & $11.90 \pm 0.02$ & $12.46 \pm 0.03$ & $11.39 \mathrm{e}$ \\
$\mathrm{T}_{2}$ & $10.96 \pm 0.01$ & $11.11 \pm 0.01$ & $11.31 \pm 0.01$ & $11.58 \pm 0.04$ & $12.01 \pm 0.05$ & $11.19 \mathrm{f}$ \\
$\mathrm{T}_{3}$ & $10.95 \pm 0.03$ & $11.03 \pm 0.03$ & $11.14 \pm 0.02$ & $11.31 \pm 0.01$ & $11.54 \pm 0.03$ & $12.08 \mathrm{~b}$ \\
$\mathrm{~T}_{4}$ & $10.96 \pm 0.01$ & $11.20 \pm 0.05$ & $11.83 \pm 0.03$ & $12.65 \pm 0.03$ & $13.78 \pm 0.02$ & $11.76 \mathrm{c}$ \\
$\mathrm{T}_{5}$ & $10.96 \pm 0.03$ & $11.12 \pm 0.02$ & $11.53 \pm 0.02$ & $12.15 \pm 0.05$ & $13.04 \pm 0.01$ & $11.38 \mathrm{e}$ \\
$\mathrm{T}_{6}$ & $10.95 \pm 0.03$ & $11.05 \pm 0.03$ & $11.20 \pm 0.03$ & $11.36 \pm 0.02$ & $12.36 \pm 0.52$ & \\
Means & $10.96 \mathrm{e}$ & $11.17 \mathrm{~d}$ & $11.53 \mathrm{c}$ & $12.13 \mathrm{~b}$ & $12.57 \mathrm{a}$ & \\
\hline
\end{tabular}

Table 2b. Effect of calcium lactate along with citric acid and ascorbic acid during storage on the weight loss of freshcut papaya cubes.

\begin{tabular}{lcccccc}
\hline \multirow{2}{*}{ Treatments } & \multicolumn{5}{c}{ Storage } & \multirow{2}{*}{ Means } \\
\cline { 2 - 6 } & $\mathbf{0}$ & $\mathbf{4}$ & $\mathbf{8}$ & $\mathbf{1 2}$ & $\mathbf{1 6}$ & \\
\hline $\mathrm{T}_{0}$ & $0 \pm 00$ & $2.11 \pm 0.04$ & $4.88 \pm 0.03$ & $7.50 \pm 0.03$ & $11.75 \pm 0.01$ & $5.25 \mathrm{a}$ \\
$\mathrm{T}_{1}$ & $0 \pm 00$ & $1.80 \pm 0.02$ & $3.62 \pm 0.02$ & $6.12 \pm 0.01$ & $10.10 \pm 0.03$ & $4.33 \mathrm{c}$ \\
$\mathrm{T}_{2}$ & $0 \pm 00$ & $1.83 \pm 0.02$ & $2.12 \pm 0.01$ & $4.23 \pm 0.02$ & $7.41 \pm 0.04$ & $3.12 \mathrm{e}$ \\
$\mathrm{T}_{3}$ & $0 \pm 00$ & $0.42 \pm 0.03$ & $1.25 \pm 0.03$ & $2.87 \pm 0.01$ & $4.69 \pm 0.03$ & $1.85 \mathrm{~g}$ \\
$\mathrm{~T}_{4}$ & $0 \pm 00$ & $1.83 \pm 0.02$ & $4.18 \pm 0.03$ & $4.35 \pm 0.04$ & $11.09 \pm 0.06$ & $4.29 \mathrm{~b}$ \\
$\mathrm{~T}_{5}$ & $0 \pm 00$ & $1.08 \pm 0.06$ & $2.18 \pm 0.02$ & $4.35 \pm 0.04$ & $7.78 \pm 0.02$ & $3.08 \mathrm{~d}$ \\
$\mathrm{~T}_{6}$ & $0 \pm 00$ & $0.54 \pm 0.02$ & $1.35 \pm 0.04$ & $3.13 \pm 0.03$ & $5.17 \pm 0.03$ & $2.04 \mathrm{f}$ \\
Means & $0 \pm 00 \mathrm{e}$ & $1.37 \mathrm{~d}$ & $2.8 \mathrm{c}$ & $4.65 \mathrm{~b}$ & $8.28 \mathrm{a}$ & \\
\hline
\end{tabular}

various storage intervals along with their interaction presented in Table 2. The lowest TSS (11.19) was recorded in $\mathrm{T}_{3}(2.4 \%$ calcium lactate $+1.7 \%$ citric acid) followed by the $\mathrm{T}_{6}$ (11.38) (2.4\% calcium lactate $+1.7 \%$ ascorbic acid) and $\mathrm{T}_{2}$ (11.39) ( $1.6 \%$ calcium lactate $+1.7 \%$ citric acid). Whereas, the highest TSS (12.28) was recorded for papaya cubes which were untreated (controlled samples) followed by $12.08{ }^{\circ}$ Brix of $\mathrm{T}_{4}(0.8 \%$ calcium lactate and $1.7 \%$ ascorbic acid). During storage the highest TSS $\left(13.94^{\circ} \mathrm{Brix}\right)$ was observed in papaya cubes for $\mathrm{T}_{0}$ (control) at $12^{\text {th }}$ day followed by $13.78^{\circ}$ Brix for
$\mathrm{T}_{4,}(0.8 \%$ calcium lactate and $1.7 \%$ ascorbic acid $)$ and $\mathrm{T}_{5}(1.6$ $\%$ calcium lactate and $1.7 \%$ ascorbic acid) on $16^{\text {th }}$ day of storage while lowest brix (10.95 ${ }^{\circ}$ Brix) was observed on zero day. By studying Pila et al. (2010) observed that when tomatoes treated with calcium chloride, Salicylic acid (SA) and Gibberellic acid (GA) samples showed lower TSS than control treatment during the 10 days of storage life analysis. Additionally, they also found that the application of calcium reduces the rate of total soluble solids decreased through retarding the ripening and respiration processes in tomato 
fruits. Hereafter, it is concluded that increase of TSS contents remained quite lower in $\mathrm{T}_{3}$ (2.4\% calcium lactate $+1.7 \%$ citric acid) treatment at $4{ }^{\circ} \mathrm{C}$ temperature which gave best shelf-life to fresh-cut papaya cubes.

Weight Loss: The statistical evaluation regarding weight loss showed that chemical treatments and storage intervals have significant $(\mathrm{P}<0.01)$ effect on weight loss of papaya cubes whereas interaction between treatments and storage intervals, also recorded to be significant. The lowest weight loss $(1.85 \%)$ was recorded in $\mathrm{T}_{3}$ followed by $(2.04 \%)$ in $\mathrm{T}_{6}(2.4 \%$ calcium lactate $+1.7 \%$ ascorbic acid). However, the highest weight loss $(5.25 \%)$ was observed for untreated (controlled) papaya cubes. During storage, the highest weight loss $(11.75 \%)$ was observed in papaya cubes for $\mathrm{T}_{\mathrm{o}}$ (control) at $16^{\text {th }}$ day. While the lowest weight loss $(0.00 \%)$ was observed in all treated and un-treated samples on 0 day. By studying Bhattarai and Gautam (2006) observed that weight loss of tomato increase with the increasing of storage intervals. Similarly, Raheem et al. (2013) also detected that during storage the weight loss of fresh cut guava sliced increased in un-treated and treated different varieties stored at different temperatures. Hereafter, it is concluded that loss of moisture contents remained quite lower in $\mathrm{T}_{3}(2.4 \%$ calcium lactate +

Table 3. Effect of calcium lactate along with citric acid and ascorbic acid during storage on the pH of fresh-cut papaya cubes.

\begin{tabular}{lcccccc}
\hline \multirow{2}{*}{ Treatments } & \multicolumn{5}{c}{ Storage } & \multicolumn{1}{c}{ Means } \\
\cline { 2 - 6 } & $\mathbf{0}$ & $\mathbf{4}$ & $\mathbf{8}$ & $\mathbf{1 2}$ & $\mathbf{1 6}$ & $4.61 \mathrm{a}$ \\
$\mathrm{T}_{0}$ & $4.29 \pm 0.01$ & $4.39 \pm 0.04$ & $4.57 \pm 0.03$ & $4.75 \pm 0.03$ & $5.06 \pm 0.04$ & $4.38 \mathrm{c}$ \\
$\mathrm{T}_{1}$ & $4.18 \pm 0.04$ & $4.24 \pm 0.02$ & $4.34 \pm 0.01$ & $4.48 \pm 0.02$ & $4.67 \pm 0.03$ & $4.31 \mathrm{e}$ \\
$\mathrm{T}_{2}$ & $4.18 \pm 0.02$ & $4.22 \pm 0.04$ & $4.29 \pm 0.01$ & $4.38 \pm 0.03$ & $4.49 \pm 0.01$ & $4.26 \mathrm{f}$ \\
$\mathrm{T}_{3}$ & $4.18 \pm 0.03$ & $4.14 \pm 0.01$ & $4.22 \pm 0.03$ & $4.31 \pm 0.01$ & $4.43 \pm 0.02$ & $4.42 \mathrm{~b}$ \\
$\mathrm{~T}_{4}$ & $4.19 \pm 0.01$ & $4.26 \pm 0.04$ & $4.38 \pm 0.02$ & $4.53 \pm 0.02$ & $4.73 \pm 0.03$ & $4.36 \mathrm{~d}$ \\
$\mathrm{~T}_{5}$ & $4.19 \pm 0.03$ & $4.23 \pm 0.03$ & $4.33 \pm 0.02$ & $4.45 \pm 0.02$ & $4.60 \pm 0.02$ & $4.51 \pm 0.04$ \\
$\mathrm{~T}_{6}$ & $4.19 \pm 0.02$ & $4.17 \pm 0.01$ & $4.24 \pm 0.01$ & $4.37 \pm 0.04$ & $4.30 \mathrm{e}$ \\
Means & $4.20 \mathrm{e}$ & $4.24 \mathrm{~d}$ & $4.34 \mathrm{c}$ & $4.47 \mathrm{~b}$ & $4.64 \mathrm{a}$ \\
\hline
\end{tabular}

Table 4. Effect of calcium lactate along with citric acid and ascorbic acid during storage on the color of fresh-cut papaya cubes.

\begin{tabular}{|c|c|c|c|c|c|c|c|}
\hline \multirow{9}{*}{$L^{*}$ value } & \multirow[t]{2}{*}{ Treatments } & \multicolumn{5}{|c|}{ Storage } & \multirow[t]{2}{*}{ Means } \\
\hline & & 0 & 4 & 8 & 12 & 16 & \\
\hline & $\mathrm{T}_{\mathrm{o}}$ & $55.10 \pm 0.01$ & $51.30 \pm 2.02$ & $44.30 \pm 1.05$ & $36.83 \pm 0.1$ & $23.51 \pm 0.42$ & $42.21 \mathrm{e}$ \\
\hline & $\mathrm{T}_{1}$ & $55.10 \pm 0.03$ & $52.50 \pm 1.1$ & $48.10 \pm 1.05$ & $42.60 \pm 0.3$ & $34.94 \pm 0.05$ & $46.65 \mathrm{~d}$ \\
\hline & $\mathrm{T}_{2}$ & $55.10 \pm 0.02$ & $53.78 \pm 1.01$ & $50.50 \pm 1.2$ & $46.50 \pm 1.05$ & $39.39 \pm 0.35$ & $49.05 \mathrm{~b}$ \\
\hline & $\mathrm{T}_{3}$ & $55.10 \pm 0.04$ & $54.12 \pm 2.03$ & $52.10 \pm 1.1$ & $48.10 \pm 1.02$ & $42.10 \pm 1.05$ & $50.30 \mathrm{a}$ \\
\hline & $\mathrm{T}_{4}$ & $55.10 \pm 0.03$ & $51.98 \pm 1.01$ & $47.95 \pm 1.02$ & $41.48 \pm 0.35$ & $33.78 \pm 0.17$ & $46.06 \mathrm{~d}$ \\
\hline & $\mathrm{T}_{5}$ & $55.10 \pm 0.01$ & $53.41 \pm 2.88$ & $49.65 \pm 1.54$ & $45.35 \pm 0.35$ & $35.23 \pm 2.71$ & $47.75 \mathrm{c}$ \\
\hline & $\mathrm{T}_{6}$ & $55.10 \pm 0.01$ & $54.08 \pm 1.02$ & $51.80 \pm 2.05$ & $46.90 \pm 1.05$ & $40.82 \pm 1.08$ & $49.74 \mathrm{ab}$ \\
\hline \multirow[t]{7}{*}{$a^{*}$ value } & $\mathrm{T}_{\mathrm{o}}$ & $11.12 \pm 0.03$ & $14.12 \pm 0.10$ & $19.62 \pm 0.18$ & $26.92 \pm 0.06$ & $34.12 \pm 0.12$ & $21.18 \mathrm{a}$ \\
\hline & $\mathrm{T}_{1}$ & $11.12 \pm 0.02$ & $13.22 \pm 0.12$ & $17.12 \pm 0.06$ & $22.47 \pm 0.08$ & $28.11 \pm 0.10$ & $18.41 \mathrm{c}$ \\
\hline & $\mathrm{T}_{2}$ & $11.10 \pm 0.02$ & $12.46 \pm 0.15$ & $15.39 \pm 0.06$ & $19.31 \pm 0.04$ & $25.12 \pm 0.07$ & $16.68 \mathrm{e}$ \\
\hline & $\mathrm{T}_{3}$ & $11.10 \pm 0.05$ & $12.05 \pm 0.05$ & $13.60 \pm 0.05$ & $15.72 \pm 0.11$ & $18.71 \pm 0.13$ & $14.24 \mathrm{~g}$ \\
\hline & $\mathrm{T}_{4}$ & $11.12 \pm 0.01$ & $13.25 \pm 0.15$ & $17.31 \pm 0.09$ & $22.69 \pm 0.07$ & $29.28 \pm 0.18$ & $18.73 \mathrm{~b}$ \\
\hline & $\mathrm{T}_{5}$ & $11.10 \pm 0.01$ & $12.51 \pm 0.20$ & $15.47 \pm 0.13$ & $19.40 \pm 0.07$ & $26.25 \pm 0.11$ & $16.95 \mathrm{~d}$ \\
\hline & $\mathrm{T}_{6}$ & $11.11 \pm 0.03$ & $12.16 \pm 0.08$ & $13.58 \pm 0.44$ & $15.93 \pm 0.04$ & $19.25 \pm 0.08$ & $14.40 \mathrm{f}$ \\
\hline \multirow[t]{7}{*}{$b^{*}$ value } & $\mathrm{T}_{\mathrm{o}}$ & $17.12 \pm 0.01$ & $20.52 \pm 0.12$ & $24.37 \pm 0.03$ & $29.42 \pm 0.03$ & $36.57 \pm 0.07$ & $25.60 \mathrm{a}$ \\
\hline & $\mathrm{T}_{1}$ & $17.11 \pm 0.02$ & $19.39 \pm 0.11$ & $22.41 \pm 0.07$ & $26.44 \pm 0.05$ & $31.53 \pm 0.02$ & $23.38 \mathrm{c}$ \\
\hline & $\mathrm{T}_{2}$ & $17.12 \pm 0.03$ & $18.47 \pm 0.07$ & $20.12 \pm 0.10$ & $23.22 \pm 0.04$ & $27.57 \pm 0.06$ & $21.30 \mathrm{e}$ \\
\hline & $\mathrm{T}_{3}$ & $17.11 \pm 0.04$ & $18.09 \pm 0.09$ & $19.18 \pm 0.12$ & $21.27 \pm 0.04$ & $24.32 \pm 0.08$ & $19.99 \mathrm{~g}$ \\
\hline & $\mathrm{T}_{4}$ & $17.11 \pm 0.01$ & $19.48 \pm 0.07$ & $22.63 \pm 0.09$ & $26.76 \pm 0.06$ & $31.91 \pm 0.04$ & $23.58 \mathrm{~b}$ \\
\hline & $\mathrm{T}_{5}$ & $17.12 \pm 0.04$ & $18.52 \pm 0.11$ & $20.21 \pm 0.06$ & $23.43 \pm 0.06$ & $27.85 \pm 0.05$ & $21.43 \mathrm{~d}$ \\
\hline & $\mathrm{T}_{6}$ & $17.11 \pm 0.02$ & $18.13 \pm 0.05$ & $19.24 \pm 0.08$ & $21.40 \pm 0.03$ & $25.14 \pm 0.06$ & $20.20 \mathrm{f}$ \\
\hline
\end{tabular}


$1.7 \%$ citric acid) treatment at $4^{\circ} \mathrm{C}$ temperature which gave the best shelf-life to fresh-cut papaya cubes.

The result regarding chemical treatments, storage intervals and their interactive effect showed significant $(\mathrm{P}<0.01)$ difference in the $\mathrm{pH}$ of papaya cubes. The lowest $\mathrm{pH}$ (4.26) was recorded in $\mathrm{T}_{3}(2.4 \%$ calcium lactate $+1.7 \%$ citric acid). However, the highest $\mathrm{pH}$ (4.61) was observed for untreated (control) papaya cubes followed by 4.42 of $\mathrm{T}_{4}(0.8 \%$ calcium lactate and $1.7 \%$ ascorbic acid). The $\mathrm{pH}$ was found significantly higher in papaya cubes $(4.64)$ at $16^{\text {th }}$ day whereas the lowest mean of means (4.20) was recorded on 0 day of storage interval. The interaction between chemical treatment and storage intervals showed highly significant difference in $\mathrm{pH}$ of fresh cut papaya cubes (Table 3). The highest $\mathrm{pH}$ (5.06) was observed in papaya cubes for $\mathrm{T}_{\mathrm{o}}$ (control) at $16^{\text {th }}$ day followed by 4.73 in $\mathrm{T}_{4}$ and 4.67 in $\mathrm{T}_{1}$ on the same day of storage. While, $\mathrm{pH}$ of papaya cubes increased when recorded as a function of storage intervals. In the same way, Raheem et al. (2013) detected that during storage, $\mathrm{pH}$ of fresh cut guava slices treated with calcium chloride and citric acid increased with increasing of storage days.

Color: The influence of calcium lactate along with citric acid and ascorbic acid on papaya cubes was analyzed by measuring the change in color values $\left(L^{*}, a^{*}, b^{*}\right)$ at each four days intervals. Initially $L^{*}, a^{*}$ and $b^{*}$ value in all samples were $50.10,11.10$ and 17.11 respectively. $L^{*}$ value of all treated and un-treated samples decreased with the passage of time. However, after the $16^{\text {th }}$ days control samples showed minimum mean value (42.21 e) while highest values (50.30 a) observed for $\mathrm{T}_{3}$ followed by (49.74 ab) in $\mathrm{T}_{6}$. Nevertheless, it has been noted that chemically treated sample preserved natural color of papaya cubes for longer than un-treated ones. The $a^{*}$ value as well as the $b^{*}$ value showed increasing pattern during storage when analyzed periodically. Waghmare and Annapure (2013) by working on fresh cut papaya resulted that all treated and un-treated samples showed decreased $L^{*}$ values during storage. While Raheem $e t$ $a l$. (2013) noticed increased $a^{*}$ and $b^{*}$ value during storage of fresh-cut guava slices but, chemically treated samples were able to maintain better $L^{*}, a^{*}, b^{*}$ values.

Sensory evaluation: After sensory evaluation of trained members of sensory penal it has been resulted that the score of taste, texture, flavor, color and overall acceptability indicated in Figure 1,2,3,4 and 5, respectively, decreased during storage. All treated and non-treated samples showed diminishing scoring trend during storage. While, $\mathrm{T}_{3}(2.4 \%$ calcium lactate $+1.7 \%$ citric acid) and $\mathrm{T}_{6}(2.4 \%$ calcium lactate $+1.7 \%$ ascorbic acid) showed highest stability to preserve sensory attributes of fresh cut papaya. Mahmud et al. (2008) noted more retention of flavor and taste of papaya during storage when it was treated with $2.5 \%$ calcium chloride. It might be due to the retention and sustainability of juice content of papaya cubes.

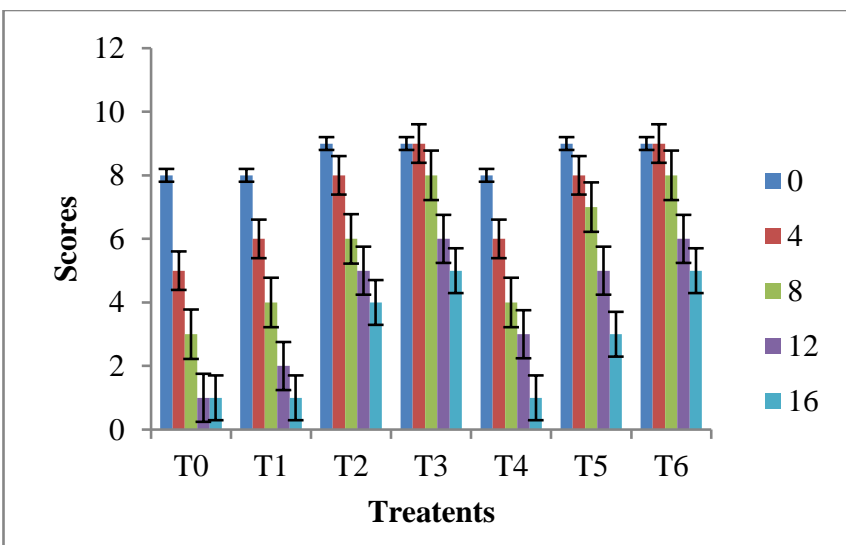

Figure 1. Effect of calcium lactate along with citric acid and ascorbic acid during storage on the taste score of fresh-cut papaya cubes.

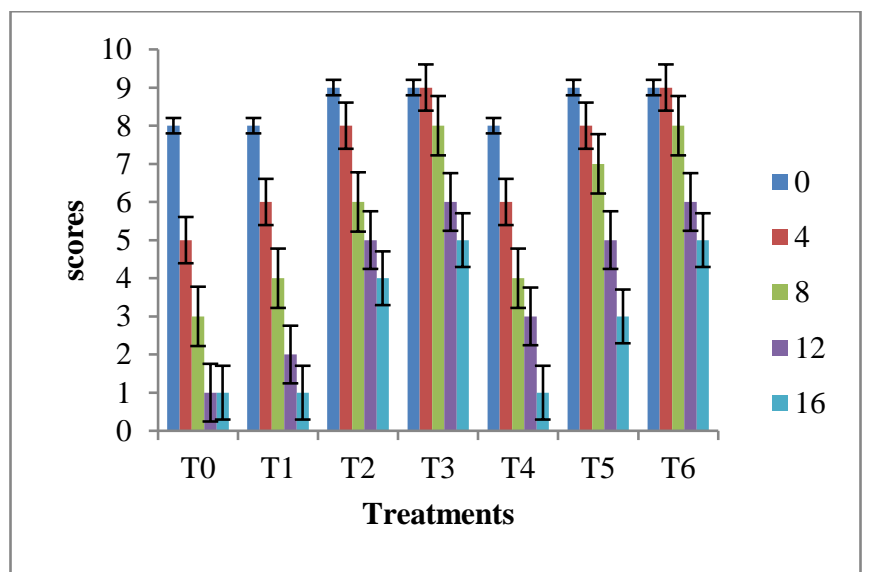

Figure 2. Effect of calcium lactate along with citric acid and ascorbic acid during storage on the texture score of fresh-cut papaya cubes.

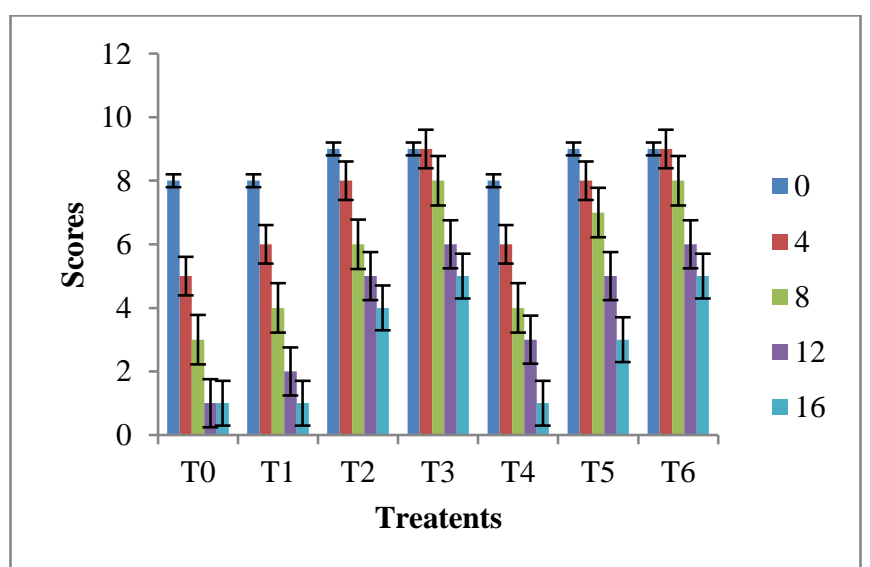

Figure 3. Effect of calcium lactate along with citric acid and ascorbic acid during storage on the flavor score of fresh-cut papaya cubes. 


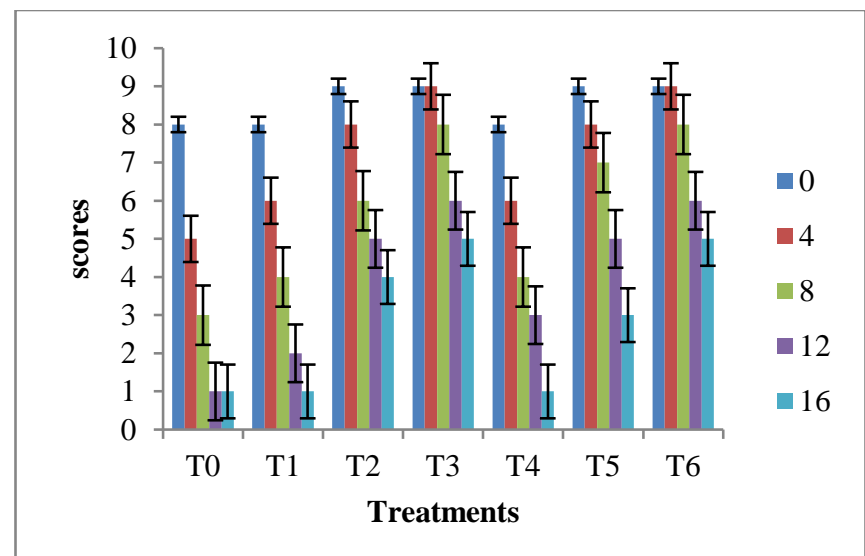

Figure 4. Effect of calcium lactate along with citric acid and ascorbic acid during storage on the color score of fresh-cut papaya cubes.

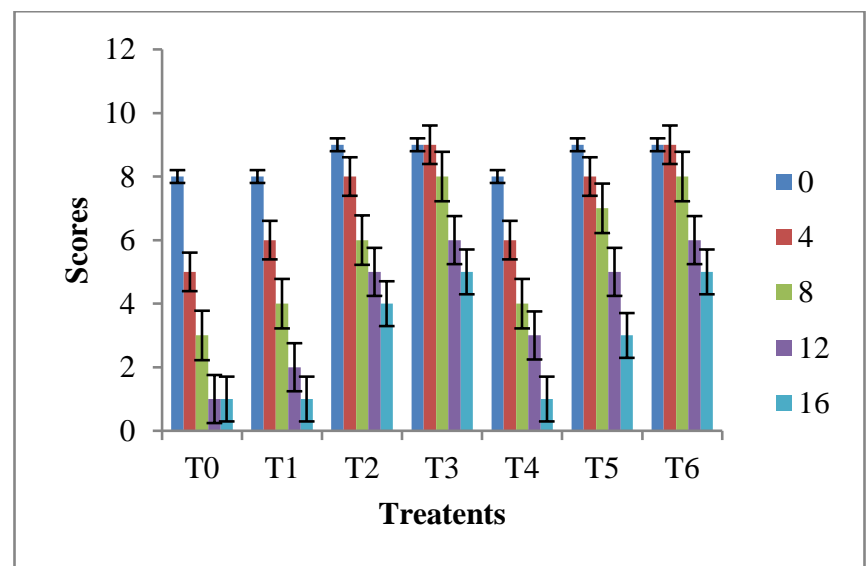

Figure 5. Effect of calcium lactate along with citric acid and ascorbic acid during storage on the overall acceptability score of fresh-cut papaya cubes.

Conclusion: The effect of calcium lactate integrated with citric acid and ascorbic acid separately were analyzed for fresh cut papaya cubes and compared with untreated (control) sample. Research findings showed that two combination treatment perform the best for maintenance of firmness, color, $\mathrm{pH}$ and TSS. One of them is $\mathrm{T}_{3}(2.7 \%$ calcium lactate $+1.7 \%$ citric acid) and other is $\mathrm{T}_{6}(2.7 \%$ calcium lactate $+1.7 \%$ ascorbic acid). Remaining treatments showed minor effect but better then control sample. Hence $\mathrm{T}_{3}$ and $\mathrm{T}_{6}$ were found to be the most useful for extending the shelf life of fresh cut papaya up to 16 days at $4^{\circ} \mathrm{C}$.

\section{REFERENCES}

GoP. 2013-14. Agricultural Statistics Year Book 2015-16. Ministry of Food, Agriculture and Livestock, Islamabad, Pakistan.
Aguayo, E., R. Jansasithorn and A.A. Kader. 2006. Combined effects of 1-methylcyclopropene, calcium chloride dip, and/or atmospheric modification on quality changes in fresh-cut strawberries. Postharvest Biol. Technol. 40:269-278.

Akhtar, A., N.A. Abbasi and A. Hussain. 2010. Effect of calcium chloride treatment on quality characteristics of loquat fruit during storage. Pak. J. Bot. 42:181-188.

Almenar, E., H. Samsudin, R. Auras, B. Harte and M. Rubino. 2008. Postharvest shelf life extension of blueberries using a biodegradable package. Food Chem. 110:120127.

Jafri, M., A. Jha, D.S. Bunkar and R.C. Ram. 2013. Quality retention of oyster mushrooms (Pleurotus florida) by a combination of chemical treatments and modified atmosphere packaging. Postharvest Biol. Technol. 76:112-118.

Jayathunge, K.G.L.R., D.K.S.N. Gunawardhana, D.C.K. Illeperuma, U.G. Chandrajith, B.M.K.S. Thilakarathne, M.D. Fernando and K.B. Palipane. 2014. Physicochemical and sensory quality of fresh cut papaya (Carica papaya) packaged in micro-perforated polyvinyl chloride containers. J. Food Sci. Technol. 51:3918-3925

Luna-Guzman, I., M. Cantwell and M.D. Barrett. 1999. Fresh-cut cantaloupe: effects of $\mathrm{CaCl}_{2}$ dips and heat treatments on firmness and metabolic activity. Postharvest Biol. Technol. 17:201-213.

Meilgaard, M.C., G.V. Civille and B.T. Carr. 2007. Sensory Evaluation Techniques, $4^{\text {th }}$ Ed. CRC Press, New York.

Noseda, B., P. Ragaert, D. Pauwels, T. Anthierens, H. Van Langenhove, J. Dewulf and F. Devlieghere. 2010. Validation of selective ion flow tube mass spectrometry for fast quantification of volatile bases produced on atlantic cod (Gadus morhua). J. Agri. Food Chem. 58:5213-5219.

Pandey, S.K. and T.K. Goswami. 2012. Modelling perforated mediated modified atmospheric packaging of capsicum. Int. J. Food Sci. Technol. 47:556-563.

Pila, N., N.B. Gol and T.V.R. Rao. 2010. Effect of postharvest treatments on physicochemical characteristics and shelf life of tomato (Lycopersicon esculentum Mill) fruits during storage. J. Agric. Environ. Sci. 9:470-479.

Raheem, M.I., M. Saeed, H.K.W. Aslam, A. Shakeel, M.S. Raza and F. Afzal. 2015. Effect of various minimal processing treatments on quality characteristics and nutritional value of spinach. J. Glob. Innov. Agric. Soc. Sci. 3:76-83.

Rocculi, P., S. Romani and M.D. Rosa. 2004. Evaluation of physico-chemical parameters of minimally processed apples packed in non-conventional modified atmosphere. Food Res. Int. 37:329-335.

Saxena, A., A.S. Bawa and P.S. Raju. 2008. Use of modified atmosphere packaging to extend shelf-life of minimally 
processed jackfruit (Artocarpushetero phyllus L.) bulbs. J. Food Eng. 87:455-466.

Sivakumar, D. and L. Korsten. 2006. Influence of modified atmosphere packaging and postharvest treatments on quality retention of litchi cv. Mauritius. Postharvest Biol. Technol. 41:135-142.

Steel, R.G.D., J.H. Torrie and D. Dickey. 1997. Principles and Procedures of Statistics: A biometrical approach, $2^{\text {nd }}$ Ed. McGraw Hill Book Co., New York.

Tirkey, B., U.S. Pal, L.M. Bal, N.R. Sahoo, C.K. Bakhara and M. Panda. 2014. Evaluation of physico-chemical changes of fresh-cut unripe papaya during storage. Food Packag. Shelf. 1:190-197.

Vij, T. and Y. Prashar. 2015. A review on medicinal properties of Carica papaya Linn. Asian Pac. J. Trop. Dis. 5:1-6.
Vilas-Boas, E.V. and A.A. Kader. 2006. Effect of atmospheric modification, 1-MCP and chemicals on quality of fresh-cut banana. J. Postharvest Biol. Technol. 39:155-162.

Waghmare, R.B. and U.S. Annapure. 2013. Combined effect of chemical treatment and/ormodified atmosphere packaging (MAP) on quality of fresh-cut papaya. Postharvest Biol. Technol. 85:147-153.

Wall, M.M., K.A. Nishijima, M.M. Fitch and W.T. Nishijima. 2010. Physicochemical, nutritional and microbial quality of fresh-cut and frozen papaya prepared from cultivars with varying resistance to internal yellowing disease. J. Food Qual. 33:131-149. 